\title{
RESEARCH
}

Open Access

\section{Flexible work arrangements in open workspaces and relations to occupational stress, need for recovery and psychological detachment from work}

\author{
Stefanie Mache ${ }^{1 *}$, Ricarda Servaty ${ }^{2}$ and Volker Harth ${ }^{1}$
}

\begin{abstract}
Background: The trend is going into the direction of flexible work arrangements in open workspaces in which employees can decide where and when to work. The aim of this study was to analyze effects of a transition to open workspaces including Activity Based Working (ABW) on employees' working conditions and their levels of occupational stress, need for recovery and psychological detachment from work.

Methods: Employees of a large technology company responded to a baseline and two follow-up measurements over one year. Data were collected via online survey assessing the employees' mental demands, workload, job autonomy, support from supervisor, team collaboration, satisfaction with communication climate and three well-being outcomes (occupational stress, need for recovery and psychological detachment from work). Descriptive statistical analyses, analyses of variance and regression analyses were applied to test the hypotheses.

Results: Significant differences in working conditions were found after the transition, e.g. reduced mental demands, but an increased workload. Job autonomy, team collaboration and satisfaction with communication climate increased. Levels of occupational stress decreased significantly over time. Regression analyses revealed substantial associations between flexible work arrangements, job resources and occupational stress.

Conclusion: The results contribute to the current knowledge on flexible work arrangements in open work spaces. They can be used to design future work settings aimed at increasing employees' well-being and job performance. Further practical implications and recommendations for future research are discussed.
\end{abstract}

Keywords: Flexible work, Mental health, Open workspaces, Working conditions

\footnotetext{
* Correspondence: s.mache@uke.de

${ }^{1}$ Institute for Occpuational Medicine and Maritime Medicine (ZfAM),

University Medical Center Hamburg-Eppendorf (UKE), Hamburg, Germany

Full list of author information is available at the end of the article
}

(c) The Author(s). 2020 Open Access This article is licensed under a Creative Commons Attribution 4.0 International License, which permits use, sharing, adaptation, distribution and reproduction in any medium or format, as long as you give appropriate credit to the original author(s) and the source, provide a link to the Creative Commons licence, and indicate if changes were made. The images or other third party material in this article are included in the article's Creative Commons licence, unless indicated otherwise in a credit line to the material. If material is not included in the article's Creative Commons licence and your intended use is not permitted by statutory regulation or exceeds the permitted use, you will need to obtain permission directly from the copyright holder. To view a copy of this licence, visit http://creativecommons.org/licenses/by/4.0/. The Creative Commons Public Domain Dedication waiver (http://creativecommons.org/publicdomain/zero/1.0/) applies to the data made available in this article, unless otherwise stated in a credit line to the data. 


\section{Background}

With the rising popularity of new forms of working, the scientific interest in flexible work arrangements such as "Activity Based Working" (ABW) and the design of office spaces is increasing as well. ABW is defined as a work design in which employees can control and organize the timing and place of their work to a great degree [1]. They can choose where they work, including the office, home, and during commuting time (e.g., in train). The key design feature of $A B W$ is the usage of open work offices with a variety of shared work spaces designed for different work tasks, so-called "activity-related workspaces" (e.g., focus and concentration rooms, meeting rooms etc.) which employees can use depending on the nature of their work activities (e.g. meetings etc.). Work spaces are chosen and used by employees based on their current work tasks with regular transitions between them [2]. These flexible work arrangements also include the principle of "desk-sharing", which means the employees do not have an assigned workstation anymore and can choose their workspace freely. The work environment is often divided into socalled neighborhoods, which ensure that colleagues from the same department still have proximity to one another. In addition, employees in ABW settings use various information technology (e.g. personal laptops and smartphones) [2,3].

Recently published research studies did not show whether ABW has more advantages or disadvantages [2]. A review by Engelen et al. summarized that $A B W$ has positive effects in the areas of interaction, communication, control of time and space, and satisfaction with the workspace; negative effects on concentration and privacy [2-4]. To date, there is a gap of studies examining relations between the concept of ABW and employees' wellbeing outcomes such as occupational stress and need for recovery $[5,6]$.

Prior studies have shown that allowing employees to manage their own working hours, choose their work location, and organize their tasks with reduced job control increases employees' perceived job autonomy $[7,8]$. This working conditions may allow employees to vary jobspecific requirements and needs $[3,9]$. Therefore, it is suggested that $\mathrm{ABW}$ offers employees a very high level of autonomy. In addition, the present study assumes that this increased autonomy in choosing optimal working conditions reduces the degree to which employees perceive their job as mentally demanding.

Contradicting results exist for social relations in ABW. Some studies found that ABW offers more opportunities for communication $[1,10]$. In contrast, other studies reported social and professional isolation, reduced feedback, and lack of support from supervisors and colleagues $[8,11,12]$. It is reported that the open office type offers fewer opportunities for face-to-face interactions and for giving and receiving support [13]. In consequence, sharing information and knowledge could be more demanding and may have a negative influence on perceived workload. In sum, we predict differences in supervisor and coworker support after a transition to ABW.

The Job Demands-Resources (JD-R) model by Demerouti, Bakker, Nachreiner, \& Schaufeli (2001) builds the theoretical framework for this study. The JD-R was chosen as an alternative to other models of employee well-being, such as the Job Demand-Control model (JDC model) and the Effort-Reward Imbalance model (ERI). The JD-R model includes a wide range of working conditions into the analyses of organizations and employees in comparison to a given and limited set of predictor variables that may not be relevant for this kind of work setting (such as in the ERI model). Furthermore, instead of focusing solely on negative outcome variables (e.g., burnout) the JD-R model includes both negative and positive indicators and outcomes of employee well-being [14].

Due to its flexibility, the model can be applied to a diverse range of different professional and operational contexts (such as ABW). The foundation of the JD-R model is that all factors, which are correlated with job stress, can be categorized in job demands and resources [14]. A key proposition of the JD-R model is that interactions between job demands and resources are important since certain job resources can buffer negative effects of psychological stress [15]. It is known that changes in work organization may implicate significant changes in job demands and resources. In relation to the JD-R model [15], changing job characteristics in case of ABW may also impact the employees' perceived occupational stress and well-being [14]. We assume that alterations in work arrangements such as ABW and increased job autonomy should have a beneficial effect on levels of employees' perceived stress.

ABW may also influences the way in which individuals perceive their need for recovery. The concept of need for recovery was deduced from the EffortRecovery theory model [16]. In this model work produces costs in terms of effort during the working day. Effort results in an array of emotional, cognitive, and behavioral symptoms that are reversed when the effort stops. Need for recovery is characterized by temporary feelings of overload, irritability, social withdrawal, lack of energy for new effort, and reduced performance [16]. We assume that ABW may create optimal and flexible working conditions. So, each employee has the autonomy and freedom of choice to decide how and when to work to achieve the best outcome. The increased flexibility and the freedom associated with organizing one's own time and job practices under diminished supervisory control may also positively affect employees' need for recovery. 
Moreover, we focus on psychological detachment from work that is defined as the ability to mentally disengage oneself from work when being away from the workplace, and is considered as a strong indicator of psychological recovery [17-19]. In the Extended Stressor-Detachment model psychological detachment is proposed as a powerful mechanism in the link between stressors and strain reactions. The model assumes that job stressors hinder psychological detachment from work. Previous research studies have provided substantial empirical support for the model by showing negative associations between job stressors (e.g., mental demands, workload, time pressure) and psychological detachment from work $[17,18,20]$. We assume that within ABW self-perceived job autonomy and flexibility in working time and location which are predicted to increase - can buffer negative effects of job demands (e.g., high levels of workload) on psychological detachment from work.

The aim of this research study was to investigate whether a transition from a normal office work setting to flexible work arrangements in open work spaces involves differences in working conditions (e.g., job demands and job resources). In addition, a further focus is on relations between flexible work arrangements in open work spaces and employees' perceived occupational stress, need for recovery and psychological detachment from work.

For this study, we predict that:

Hypothesis 1: Levels of perceived job demands (i.e. mental demands and workload) are significantly lower after the transition to open work spaces including $A B W$.

Hypothesis 2: Levels of perceived job resources (i.e. job autonomy, support from supervisor, team collaboration and communication) are significantly higher after the transition to open work spaces including $A B W$. Hypothesis $3 a$ : Levels of occupational stress are significantly lower after the transition to open work spaces including $A B W$.

Hypothesis 3b: Levels of need for recovery are significantly lower after the transition to open work spaces including $A B W$.

Hypothesis 3c: Levels of psychological detachment from work are significantly higher after the transition to open work spaces including $A B W$.

Hypothesis 4: Flexible working arrangements in open work spaces are significantly negatively related to occupational stress and need for recovery and positively related to psychological detachment from work. Hypothesis 5: Job autonomy moderates the relationship between flexible working arrangements in open work spaces and occupational stress, need for recovery and psychological detachment from work.

\section{Materials and methods}

\section{Study design and setting}

The study was designed as a longitudinal study, because differences over time should be shown. Data collection took place in 2017/2018 from employees of a large technology company. A transition to open work spaces including $\mathrm{ABW}$ was planned for the head quarter. Consistent with the principles of $\mathrm{ABW}$, the main organizational changes were implemented. The transition has been communicated to the employees.

Three data measurements were administered via online surveys. The first survey (T0) was distributed one month before changing the workplace into open work spaces including ABW. The second survey (T1) was circulated three months after the change and the third wave of data (T2) one year after the change.

\section{Study sample and recruitment of participants}

All employees working in ABW with flexible open workspaces were recruited. Work tasks included administrative and finance related tasks. Recruitment was performed via email and/or direct communication to contribute to this study.

Employees were included in the study based on the following criteria: (1) office representatives, (2) working full time, (3) working experience with at least one year of service, (4) German speaking employee. Every participant gave written informed consent. Employees were excluded from the study based on the following criteria: 1) employees working part-time, 2) trainees, 3) employees, who do not work in the activity based work environment.

The German Headquarter in Hamburg comprises 203 employees. Out of the 121 eligible participants contacted (all employees working in the office implementing $\mathrm{ABW}), 103$ employees completed the first questionnaire (T0; $81.4 \%$ response rate). The response rate of the first follow-up wave (T1) was $78.2 \%$, and the second followup wave (T2) had a $72.8 \%$ response rate. Participants were only included if they had provided data for all three assessments ( $N=71$ employees, $59 \%$ of the initial group). No significant differences could be found between responders and non-responders in the first or second follow-up survey with regard to socio-demographic or work-related variables.

\section{Survey procedure}

Employees were requested to complete an online questionnaire before moving in open work spaces (baseline), after 3 months (follow-up survey 1) and after 12 months (follow-up survey 2). The surveys were conducted by using a secure web-based survey system, via links within e-mail messages.

After receiving the signed consent form from the physicians, the link for the survey was sent to each participant. 
A link for the follow-up survey 1 was emailed three month after the transition, the link for the follow-up survey 2 was emailed twelve months later.

\section{Measurement}

All participating employees were asked to complete three online surveys (before transformation and two follow-up surveys). All measurements were conducted as self-reports, using a secure and widely used external online survey collection service. Links to the surveys were e-mailed directly to the employees. All surveys contained anonymous data only.

\section{Flexible work arrangements}

According to van Steenbergen et al. (2018), Activity Based Working was assessed by using five items: (a) "I decide for myself where (office, home, elsewhere) and when I work," (b) "I do not have my own personal desk (flex-desk concept)" c) "In the office, I work in an 'activity-related' manner (e.g., using spaces for concentration, communication, meetings)" d) "I use information technology (e.g., smartphone, laptop), so I can work at any chosen location or time," (e) "I regularly work remotely with my colleagues". Items were scored on a 5-point Likert scale ranging from 1 (=totally disagree) to 5(=totally agree) [19]. The Cronbach's alpha coefficients of the ABW scales were 0.78 (ABWT0), 0.80 (ABWT1), and 0.79 (ABWT2), respectively.

\section{Job demands}

Mental demands were assessed using the Copenhagen Psychosocial Questionnaire (COPSOQ I) [21]. Items were scored on a 5-point Likert scale ranging from 1 (= always) to 5 (= never). An example of the item is: "My work requires a high level of concentration" [21]. Reliability and validity of the COPSOQ I are good [21].

Workload was measured with 4 items from the Kurzfragebogen zur Arbeitsanalyse (KFZA) instrument [22]. A sample item is: "I have too much work". Items were scored on a 5-point Likert scale ranging from 1 (=very little) to 5 (=very much). Cronbach's alpha coefficients ranged between 0.75 and 0.86 .

\section{Job resources}

Job autonomy and team collaboration were measured using a 3-item scale of the KFZA instrument, e.g., "Can you decide for yourself how you execute your work?". Items were scored on a 5-point Likert scale ranging from 1 (never) to 5 (=always). The reliability coefficients were 0.81 (T0), 0.79 (T1), and 0.81 (T2). Coworker support was assessed with three items of the KFZA including "Can you ask your colleagues for feedback if necessary?" ( 1 = never, 5 = always; alpha coefficients were 0.78 (T0), 0.80 (T1), and 0.75 (T2)) [22].
Supervisor support was assessed with 3 items of the COPSOQ, such as "Can you ask your supervisor for help if necessary?" ( $1=$ never, $5=$ always; alpha coefficients were $<.80$ at all three measurements).

A 5-items scale of the Communication Satisfaction Questionnaire (CSQ) was used to measure changes in satisfaction with communication climate and supervisory communication [23, 24]. Items were used with a Likert type scale ranging from very satisfied (1) to very dissatisfied (7). As an example: "My supervisor offers guidance for solving job-related problems." The questionnaire shows good psychometric properties [25]. Alpha coefficients ranged between $0.73-0.82$.

\section{Well-being outcomes (occupational stress, need for recovery, psychological detachment)}

Occupational stress symptoms were measured using the 4-item subscale of the COPSOQ II [26]. Items were scored on a 5 -point Likert scale ranging from $1=$ not at all to $5=$ all the time. An example item is "In the last month, how often have you been upset because of something that happened unexpectedly?" Research supports the psychometric qualities of the scale [26]. Alpha coefficients were 0.75 (T0), 0.73 (T1), and 0.76 (T2) [27].

Need for recovery (NFR) was measured by using the German version of the NFR after work scale that included 11 items on a dichotomous (yes/no) scale [27]. Typical items of this scale are: "Because of my job, at the end of the working day I feel rather exhausted", "I find it hard to relax at the end of a working day". The sum score is calculated by adding the individual's scores on the 11 items. Higher scores indicate a higher degree of need for recovery after work [27].

Psychological detachment from work was assessed with the same named 4-item subscale from the Recovery Experience Questionnaire [28]. The scale ranges from 1 (= I do not agree at all) to 5 (= I fully agree), with higher scores indicating higher psychological detachment. An example item is: "During leisure time, I forget about work." The scale shows good psychometric properties [28]. Alpha coefficients were 0.80 (T0), 0.78 (T1) and 0.79 (T2).

Sociodemographic variables included age, gender, years of working experience, job position, marital status and presence of children (see Table 1).

\section{Statistical analyses}

When variables were measured by multiple items, scale means were calculated and used in all analyses. All items relevant for hypotheses testing were continuous variables. For regression analyses, especially for moderation analyses, all variables were centered at their means to address potential problems of multicollinearity [29].

The data were tested for normal distribution. Normal distribution can be identified by looking at skewness and 
Table 1 Sociodemographic of the study sample

\begin{tabular}{|c|c|c|}
\hline Variables & $N$ & $\%$ \\
\hline \multicolumn{3}{|l|}{ Gender $(n=71)$} \\
\hline Female & 38 & 53.5 \\
\hline Male & 33 & 46.5 \\
\hline \multicolumn{3}{|l|}{ Age $(n=71)$} \\
\hline$\leq 29$ years & 13 & 18.3 \\
\hline 30-39 years & 33 & 46.5 \\
\hline $40-49$ & 17 & 23.9 \\
\hline$\geq 50$ years & 8 & 11.3 \\
\hline \multicolumn{3}{|c|}{ Relationship status $(n=70)$} \\
\hline Single & 15 & 21.4 \\
\hline In a relationship & 55 & 78.6 \\
\hline \multicolumn{3}{|l|}{ Children $(n=70)$} \\
\hline Yes & 37 & 52.9 \\
\hline No & 33 & 47.1 \\
\hline \multicolumn{3}{|c|}{ Work experience $(n=71)$} \\
\hline $1-2$ years & 16 & 22.5 \\
\hline $3-5$ years & 27 & 38.1 \\
\hline more than 5 years & 28 & 39.4 \\
\hline \multicolumn{3}{|c|}{ Job position level $(n=71)$} \\
\hline Assistant & 13 & 18.3 \\
\hline Associate & 23 & 32.4 \\
\hline Specialist & 28 & 39.4 \\
\hline Manager & 7 & 9.9 \\
\hline
\end{tabular}

Note: Sample size differs between $n=70$ and $n=71$ due to missing data

kurtosis values, histograms or statistical tests [30]. All of this output was generated and interpreted, but concrete confirmation of the normality assumption in numbers was tested on the basis of the Shapiro Wilk test. In contrast to the Kolmogorov-Smirnov test, the Shapiro Wilk test is adapted for small sample sizes [31]. The ShapiroWilk-Test indicated that data was normally distributed $(p=.32)$, skewness and kurtosis of the variables were mainly beyond the threshold of $<1.0$. Therefore, we used parametric tests.

A check for outliers was conducted by creating box-andwhiskers plots. The whiskers of the plots showed no outliers.

We analyzed the differences of the transition in working conditions (job demands and resources) as well as on the outcome variables by using repeated measures of univariate and multivariate analysis of variance (RM ANOVA, RM MANOVA) (hypotheses 1-3). In order to further examine the significance and magnitude of the effects of time, we inspected post-hoc multivariate effects of time and conducted pair-wise comparisons. In addition, we performed Bonferroni corrections due to multiple testing. Effect sizes (d) were interpreted as follows: $0.01-0.059=$ small; $0.059-0.138=$ medium; and $\geq$
$0.138=$ large effect [32]. A Pearson correlation matrix was conducted to see the relations between flexible working arrangements, job demands, job resources and the three well-being outcomes (occupational stress, need for recovery and psychological detachment) (hypothesis 4). No excessive correlations (all r's <.60) were analyzed (see Table 3). Therefore, we conclude that multicollinearity does not occur here. The results of the Mauchly's tests of Sphericity show that sphericity has not been violated $(p>.05)$.

Multiple regression analyses were used to examine the relationship of the predictors (flexible work arrangements, job demands and resources) and occupational stress, need for recovery and psychological detachment as an outcome (hypotheses 4,5 ). For stepwise regression analysis a sample size of $N=71$ would be too small [29]. For moderation analysis, all variables were centered at their means to prevent potential problems of multicollinearity [29] and make lower-order effects interpretable [30]. $R^{2}$ was measured to examine the amount of variability in the outcome which could be explained by the predictors.

Regarding the moderating effect of job autonomy on the linkages between flexible working arrangements and the three well-being outcomes, a moderated multiple regression analysis was performed (hypothesis 5). The flexible work arrangement scale and job autonomy scale were centered at their means before computing the interactions. In addition, a simple slopes analysis was performed. We controlled for the influence of sociodemographic variables. We used standardized regressions weights $(\beta)$ to assess the strengths of association between the variables. Based on Cohen's recommendations [73], $\beta=0.1$ was interpreted as a weak, $\beta=0.3$ as a moderate, and $\beta=0.5$ as a strong association. We defined $p<0.05$ as level of significance. All provided $p$-values were two-tailed. Data were calculated using the SPSS $^{\oplus}$ software package for social sciences; Version 23.0.

Statistical analyses were carried out using IBM SPSS Statistics for Windows V.23.0 (IBM Corp; released 2015; Armonk, New York, USA).

\section{Results}

\section{Descriptive statistics}

Employees' sociodemographic characteristics at baseline are given in Table 1. Half of the respondents were female (53.5\%); $78 \%$ were in a relationship and $52.9 \%$ had children, mean age was 39 years ( $\mathrm{SD}=9.5$ years). The majority of the participating employees worked for more than 5 years in the current position (39.4\%).

Means and standard deviations for differences in flexible work arrangements, job demands, job resources and well-being outcomes are presented in Table 2 . 
Table 2 Differences in means and standard deviations for job demands, job resources, and well-being outcomes before and after the transition to open work spaces

\begin{tabular}{|c|c|c|c|c|c|c|c|}
\hline \multirow[t]{2}{*}{ Variables } & \multicolumn{2}{|l|}{ T0 } & \multicolumn{2}{|l|}{$\mathrm{T} 1$} & \multicolumn{2}{|l|}{$\mathrm{T} 2$} & \multirow{2}{*}{$\begin{array}{l}\text { Effect time } \\
p\end{array}$} \\
\hline & M & SD & $\bar{M}$ & SD & M & SD & \\
\hline Flexible work arrangements (scale) & $3.54^{1,2}$ & 1.35 & $5.14^{0}$ & 1.69 & $5.09^{0}$ & 1.62 & .00 \\
\hline Desk sharing & $3.58^{1,2}$ & 1.47 & $5.04^{0}$ & 2.01 & $5.13^{0}$ & 2.14 & .00 \\
\hline Activity based working & $3.84^{1,2}$ & 1.95 & $5.89^{\circ}$ & 1.87 & $5.93^{0}$ & 1.94 & .00 \\
\hline Flexibility in Time and Location & $3.38^{1,2}$ & 1.28 & $4.58^{\circ}$ & 1.94 & $4.71^{\circ}$ & 1.89 & .00 \\
\hline Information Technology & $4.01^{1,2}$ & 1.79 & $5.01^{0}$ & 2.01 & $5.63^{0}$ & 2.14 & .00 \\
\hline Working outside the office & $3.89^{1,2}$ & 1.84 & $4.87^{0}$ & 2.17 & $4.91^{\circ}$ & 2.21 & .00 \\
\hline \multicolumn{8}{|l|}{ Job demands } \\
\hline Mental demands & $3.95^{1,2}$ & 1.15 & $3.78^{\circ}$ & 1.21 & $3.41^{\circ}$ & 1.24 & .02 \\
\hline Workload & $3.68^{1,2}$ & 1.04 & $4.02^{2}$ & 0.98 & $4.17^{1}$ & 1.09 & .02 \\
\hline \multicolumn{8}{|l|}{ Job resources } \\
\hline Job autonomy & $3.48^{1,2}$ & 1.12 & $3.71^{2}$ & 1.06 & $3.96^{1}$ & 1.01 & .03 \\
\hline Collaboration team & $4.01^{2}$ & 1.27 & $4.10^{2}$ & 1.22 & $4.51^{1}$ & 1.25 & .04 \\
\hline Support supervisor & $3.78^{\mathrm{ns}}$ & 1.02 & $3.71^{\mathrm{ns}}$ & 1.03 & $3.75^{\mathrm{ns}}$ & 1.02 & .09 \\
\hline Supervisory communication & $4.71^{\mathrm{ns}}$ & 1.69 & $4.58^{\mathrm{ns}}$ & 1.61 & $4.67^{\mathrm{ns}}$ & 1.65 & .08 \\
\hline Communication satisfaction: climate & $5.68^{\text {ns }}$ & 1.51 & $5.95^{\mathrm{ns}}$ & 1.47 & $6.28^{\mathrm{ns}}$ & 1.53 & .19 \\
\hline \multicolumn{8}{|l|}{ Well-being Outcomes } \\
\hline Occupational stress & $3.87^{2}$ & 1.05 & $3.61^{\mathrm{ns}}$ & 1.08 & $3.51^{\circ}$ & 1.01 & .01 \\
\hline Need for recovery & $4.85^{\text {ns }}$ & 1.02 & $4.71^{\mathrm{ns}}$ & 1.03 & $4.69^{\mathrm{ns}}$ & 1.09 & .61 \\
\hline Psychological detachment from work & $3.11^{\mathrm{ns}}$ & 1.10 & $3.19^{\mathrm{ns}}$ & 1.06 & $3.20^{\mathrm{ns}}$ & 1.09 & .86 \\
\hline
\end{tabular}

Note. 0 significantly differs from pre-measure, 1 significantly differs from post-measure $1 ; 2$ significantly differs from post-measure $2 ; n s$ no significant differences from other measures; $p$ values for univariate analyses

We conducted a RM MANOVA to check whether flexible work arrangements (e.g. $\mathrm{ABW}$ ) were higher at $\mathrm{T} 1$ and $\mathrm{T} 2$ than at T0. The results of the combined flexible work arrangements showed a significant increase over time $F(10,285)=39.94, p<0.01$. The univariate analyses showed significant effects of time on the variables desk sharing, activity based working, flexibility in time and location, information technology use, working outside the office (see Table 2).

\section{Differences in job demands after the transition to open work spaces}

Lower levels of perceived job demands (workload, mental demands) were assumed in Hypothesis 1. The RM ANOVA showed a significant effect of time on workload $(F(2,210)=4.16, p=.02 ; \mathrm{d}=.03)$. Pairwise comparisons showed that workload was significantly higher a year after the transition $(\mathrm{T} 2)(\mathrm{M}=4.17, \mathrm{SD}=1.09)$ than before the transition (T0) $(\mathrm{M}=3.68, \mathrm{SD}=1.04), p<.05$.

The RM ANOVA exposed a significant effect of time on mental demands $(F(2,210)=3.75, \mathrm{p}=.02 ; \mathrm{d}=.03)$. Pairwise comparisons showed a significant decrease in mental demands a year after the transition (T2) $(\mathrm{M}=$ $3.41, \mathrm{SD}=1.24)$ than at $\mathrm{T} 0(\mathrm{M}=3.95, \mathrm{SD}=1.15), p<.01$, $\mathrm{d}=.05$.
All in all, hypothesis 1 was partly supported, in that we found significant reduced levels of mental demands after the transition to open work spaces.

\section{Differences in job resources after the transition to open work spaces}

We also tested Hypothesis 2 to examine effects of the transition on the job resources (autonomy, supervisor support, team collaboration, communication, etc.).

Job autonomy showed effects on time $F(2,210)=3.61$, $p=0.03, \mathrm{~d}=.03)$. A pairwise comparison specified that job autonomy was significantly higher at $\mathrm{T} 1(\mathrm{M}=3.71$, $\mathrm{SD}=1.06 ; p<.05)$, and at $\mathrm{T} 2 \quad(\mathrm{M}=3.96, \quad \mathrm{SD}=1.01$; $\mathrm{p}<.05$, than at baseline $(\mathrm{T} 0)(\mathrm{M}=3.48, \mathrm{SD}=1.12)$.

In addition, we examined effects on time for differences in collaboration between colleagues after a change to $\mathrm{ABW} F(2,210)=3.24, p=0.04 ; \mathrm{d}=.03$ ) (hypothesis 2c). Team collaboration was rated significantly higher a year after the change $(\mathrm{T} 2)(\mathrm{M}=4.51, \mathrm{SD}=1.25)$ than before the change (T0) $(\mathrm{M}=4.01, \mathrm{SD}=.1 .27 ; p<.01)$.

We also tested whether levels of supervisor support, communication climate and supervisory communication differ after a transition to ABW. Univariate results revealed no significant differences (see Table 2).

In sum, hypothesis 2 can be partly confirmed. 
Differences in occupational distress, need for recovery and detachment from work after the transition to open work spaces

In addition, we found a significant decrease for occupational stress after the transition at T2 $(F(1,140)=6.47$, $p<.01 ; \mathrm{d}=.04$ ) (see Table 2). The results of one-way repeated variance analyses showed no significant differences in psychological detachment from work and need for recovery $(p>.05)$. So, only hypothesis 3 a was supported.

Relations between flexible work arrangements (ABW) and employees' well-being outcomes

A Pearson correlation matrix was performed in order to check the correlations between flexible working arrangements, the three dimensions of employee well-being and job autonomy (hypotheses 4). Table 3 shows the correlations between the variables. There are significant correlations $(p<.05)$ between the different dimensions. In detail, we found a significant negative correlation between levels of flexible work arrangement and perceived occupational stress $(r=-.19, p<.05)$ as well as for need for recovery $(r=-.21, p<.01)$ and a significant positive correlation for psychological detachment $(r=.15, p<.05)$. The correlation matrix shows that there is no significant correlation between gender and the variables used. In addition, there is a negative correlation between age and occupational stress $(r=-.21, p<.01)$ and a positive association between age and need for recovery $(r=.25, p<.01)$.

The control variables correlated only with a few of the independent and the dependent variables. Only age and work experience correlated with the three well-being outcomes. Therefore, they were used as control variables in the regression analysis. According to the regression analysis (see Table 4), there was indeed a significant negative relationship between flexible working arrangements and occupational stress $(\beta=-.19, p<.01)$. In accordance with the regression analysis, flexible working arrangements were negatively related to the need for recovery $(\beta=-.15, p<.05)$. Referring to the multiple regression analysis, there is also a positive relationship between flexible working arrangements and psychological detachment. Therefore, hypothesis 4 was confirmed.

Hypothesis 5 predicted interaction effects of job autonomy on the relationship between flexible working arrangements and the different dimensions of employee well-being. The last step in Table 4 shows that the interaction term between flexible working arrangements and job autonomy was significant for occupational stress $(\beta=.12, p<.05)$. The results revealed that the relationship between flexible working arrangement and occupational stress was significant when job autonomy was at high levels, but the relationship was not significant when job autonomy was low. In addition, the results presented in Table 4 show that job autonomy did not moderate the negative relationship between flexible work arrangements and need for recovery as well as for psychological detachment from work. The interaction effects were not significant. Therefore, hypothesis 5 was partly supported.

\section{Discussion}

The present study set out to examine differences in working conditions after a change to open work spaces

Table 3 Correlations between working conditions and well-being outcomes

\begin{tabular}{|c|c|c|c|}
\hline \multirow[t]{2}{*}{ Independent variables } & \multicolumn{3}{|c|}{ Dependent variables } \\
\hline & $\begin{array}{l}\text { Occupational } \\
\text { stress }\end{array}$ & $\begin{array}{l}\text { Need for } \\
\text { recovery }\end{array}$ & $\begin{array}{l}\text { Psychological detachment } \\
\text { from work }\end{array}$ \\
\hline Age & $-.21^{* *}$ & $.25^{* *}$ & .10 \\
\hline Work experience & $.15^{*}$ & $.11^{*}$ & $.15^{*}$ \\
\hline Flexible work arrangements (ABW) (scale; T2) & $-.19^{*}$ & $-.21^{* *}$ & $.15^{*}$ \\
\hline "I do not have my own personal desk (flex-desk)" & $.21^{*}$ & $.17^{*}$ & .07 \\
\hline "I decide for myself where (office, home, elsewhere) and when I work" & $-.25^{* *}$ & $-.18^{* *}$ & $.14^{*}$ \\
\hline $\begin{array}{l}\text { "I use information technology (e.g., smartphone, laptop), so I can work at any chosen } \\
\text { location or time" }\end{array}$ & $.17^{*}$ & $.11^{*}$ & $-.20^{* *}$ \\
\hline "I regularly work remotely with my colleagues" & $-.12^{*}$ & $-.18^{* *}$ & -.09 \\
\hline $\begin{array}{l}\text { "In the office, I work in an 'activity-related' manner (e.g., using spaces for concentration, } \\
\text { communication, meetings)" }\end{array}$ & $.14^{*}$ & $.16^{*}$ & .09 \\
\hline Mental demands (T2) & $.30^{* *}$ & $.36^{* *}$ & $-.19^{* *}$ \\
\hline Workload (T2) & $.39^{* *}$ & $.31^{* *}$ & $-.25^{* *}$ \\
\hline Job autonomy (T2) & $-.16^{*}$ & $-.21^{* *}$ & .08 \\
\hline Collaboration team (T2) & $-.21^{* *}$ & $-.19^{*}$ & .11 \\
\hline Support supervisor (T2) & -.17 & -.10 & $.14^{*}$ \\
\hline Supervisory communication (T2) & $-.19^{*}$ & $-13^{*}$ & .10 \\
\hline Communication satisfaction: climate (T2) & -.11 & -.09 & .09 \\
\hline
\end{tabular}


Table 4 Results of multiple regression analysis for the interaction effects on occupational distress, psychological detachment from work and need for recovery

\begin{tabular}{|c|c|c|c|c|c|c|c|c|c|}
\hline & \multicolumn{3}{|c|}{ Occupational stress } & \multicolumn{3}{|c|}{ Need for recovery } & \multicolumn{3}{|c|}{ Psychological detachment from work } \\
\hline & Step 1 & Step 2 & Step 3 & Step 1 & Step 2 & Step 3 & Step 1 & Step 2 & Step 3 \\
\hline \multicolumn{10}{|l|}{ Variable } \\
\hline Age & $-.17^{*}$ & $-.15^{*}$ & $-.14^{*}$ & $.19^{*}$ & $.18^{*}$ & $.16^{*}$ & .08 & .06 & .05 \\
\hline Work experience & -.11 & -.09 & -.08 & -.09 & -.06 & -.05 & $.14^{*}$ & $.12^{*}$ & $.12^{*}$ \\
\hline Flexible work arrangements (ABW) & $-.19^{*}$ & $-.18^{*}$ & $-.17^{*}$ & $-.15^{*}$ & $-.13^{*}$ & $-.11^{*}$ & .10 & .09 & .08 \\
\hline Job autonomy & & $-.16^{*}$ & $-.14^{*}$ & & $-.19^{*}$ & $-.17^{*}$ & & .08 & .05 \\
\hline ABW $\times$ job autonomy & & & $.12^{*}$ & & & -.06 & & & .07 \\
\hline$R^{2}$ & .28 & .33 & .39 & .16 & .18 & .20 & .10 & .14 & .15 \\
\hline
\end{tabular}

Note: The coefficients are standardized $B$ weights. ${ }^{*} p<.05 ;{ }^{* *} p<.01$

including $\mathrm{ABW}$ on employees' job demands, job resources, occupational stress, psychological detachment from work and need for recovery. The results revealed relations between flexible working arrangements, occupational stress and need for recovery. The findings indicated potentially beneficial effects of autonomy on employees' perceived stress levels.

\section{Differences in job demands and job resources after the transition to open work spaces}

We found an increase in perceived workload after the transition to open work spaces. This result was surprising and may be interpreted with the "autonomy paradox" [33]. The paradox is that when workers are given more autonomy and freedom, instead of working less, they work more and longer [33]. In fact, recent studies have shown that flexible working increases work intensity, working hours, and overtime [34, 35]. This type of control over one's work could have also been given to workers alongside other responsibility, and possibly increased workload as well [36].

We also found a significant difference in perceived job autonomy in that it increased after the transition to open work spaces including ABW. All employees had the flexibility to work at the office or at home. Besides, employees were free in the decision to change their working routines (e.g., work time, location). This might have increased feelings of perceived job autonomy. Medik and Stettina (2014) also reported that most of their study participants associated flexible work arrangements with greater job autonomy and flexibility in working time and location [37]. A meta-analysis by Engelen et al. reported on several studies that show an increase in perceived job control in $\mathrm{ABW}$ working environments where employees can decide when and where to do the work $[2,3,38]$.

This study also showed significant differences in mental demands after the transition to flexible work arrangements in open work spaces. The transition to ABW seemed to make working somewhat less demanding at least at the longer term. This parallels earlier studies which demonstrated that $\mathrm{ABW}$ reduces mental demands and time pressure $[1,7,39]$. An explanation can be found in a study by Kelliher and Anderson (2008) which reports that flexible work designs allow employees to schedule their work in a way that suits their situation best, thereby saving time and energy [40]. Engelen et al. (2019) concluded that ABW can be promoted as providing some benefits for perceptions of the work environment. However, they also require more high-quality research to strengthen the evidence base further and to establish ABW's effects [2].

In addition, we found that employees experienced higher levels of collaboration between employees one year after the introduction of flexible work arrangements with ABW. Two previously published studies have been found analyzing relations between $\mathrm{ABW}$ and collaboration [41, 42]. Robertson et al. found that collaboration was significantly higher after the change to $\mathrm{ABW}$ in comparison to the control group [42]. Blok et al. (2012) reported that ABW supported cooperation with colleagues. Negative effects have been discussed in relation to the length employees worked outside the office [34]. The results also demonstrated no significant improvements in satisfaction with communication climate. The systematic review by Engelen et al. (2019) reported several studies that show positive effects on communication [2]. Ten Brummelhuis et al. (2012) reported ABW as positively associated with improved connectivity as well as effective and efficient communication [1]. In addition, a study by De Been et al. (2015) indicated that employees experience more communication, information and knowledge exchange as a result of $\mathrm{ABW}$ and open workspaces [33]. However, De Been et al. (2015) stated that satisfaction with communication was lower in flex offices than in combi offices. The authors base the result on the fact that coworkers are easier to find and approach in combi offices than in flex offices. The location of an employee directly affects the possibility of making contact with other colleagues [33]. 
Relations between flexible work arrangements and wellbeing outcomes

We found a significant decrease in perceived occupational stress after the transition to flexible work arrangements in open work spaces. As theoretical assumed the increase of job autonomy in the decision where and when to work had a positive buffering effect on occupational stress perception and need for recovery. This finding is in line with a controlled trail study by Moen et al. (2016) showing that employees who participated in a pilot work flexibility program reported reduced levels of stress and exhaustion than employees within the same company who did not participate. They explained their results by increased job control and autonomy. Importantly, the participating employees were also more efficient and more productive on the job [43].

We did not find support for the assumption that the change would cause less need for recovery over the short and/or long term. As an explanation, it may need more time for flexible work arrangements to have a significant influence on the need for recovery than expected. Previous studies showed small effects on employees' perceptions of exhaustion or fatigue $[1,44,45]$. Ten Brummelhuis et al. (2012) reported no direct associations between working in an $\mathrm{ABW}$ environment and daily exhaustion [1].

The authors explained this result with the assumption that the advantageous effects of being connected to work (intrinsic motivation, absorbation) outweigh disadvantageous [1]. Personality characteristics may also have influenced the study findings. It is possible that the selected employees are open to change, extravert, and like social interactions with others. These employees may value frequent interactions with others, whereby engagement increases while exhaustion decreases [1].

This was one of the first studies to examine possible effects of flexible work arrangements on psychological detachment from work. We found no significant changes in psychological detachment from work after changing to flexible work arrangements in open work spaces. A study by Mellner et al. (2016) reported that working flexible at different places and time is not related to psychological detachment [46]. They concluded that psychological detachment is more likely to be explained by individual personality characteristics than by working environments [46].

The interacting effect of job autonomy on psychological detachment from work could also not be confirmed. An explanation could also be that the individual character of employees plays the most important role. It seems that employees do not need increased job autonomy to perceive a higher level of detachment from work. No comparative studies exist to discuss this result in more detail.

\section{Strengths and limitations}

In order to gain good insight into the effects, it is important to measure the situation before the implementation takes place as well as several times afterwards [47]. Thus, short-term effects caused by the change towards the flexible work arrangement should have disappeared. A strength of this study was its study design with two follow-up measurements. Most previously studies on this topic analyzed only after the transition but not before [48]. This study has several limitations. We did not include a control group, as all employees of the department changed to open work spaces including ABW. So, we cannot fully conclude that the effects were affected by the transition. Other changes in the company might have had an influence on the results. The external validity of the results is limited. We only include one organization in Germany so the findings cannot be generalized to other organizations. In addition, the sample size is relatively small. This may affect the reliability of the study results. Another major limitation of small studies is that they can over-estimate the magnitude of an association. In total, there is nothing wrong with conducting well-designed small studies; they just need to be interpreted carefully. Therefore, it is important not to make strong conclusions.

Furthermore, the discussion of study results has to rely on a limited base of literature. Up to now there is only a small amount of scientific studies on flexible work arrangements such as ABW. As the discussion showed, research results on flexible work arrangements can be adduced for reference, although it must be taken into consideration that there are several preconditions that differ.

\section{Practical implications and future research}

Based on our research findings some practical advices can be highlighted: Organizations should wisely reflect if a change to open work spaces including ABW will achieve the anticipated goals. Overviewing the research findings, $A B W$ might not be the best working surrounding and concept for all employees and job tasks. For job tasks that need high levels of inter-team communication and collaboration, $\mathrm{ABW}$ and open workspaces might be valuable. In contrast, job tasks that need high levels of intra-team communication and collaboration should be performed in traditional combi-offices [13]. Building an open work culture with increased autonomy, decisionmaking, information sharing and collaboration in teams should be a central goal when changing to flexible work arrangements such as ABW [41]. For a successful change, communication is a main factor. Open communication through numerous mediums and employee participation in the process are central success factors [49]. Goal orientated leadership is essential since managing employees is totally different when it is no longer obvious were, when and what employees are working on. 
Trust in employees is essential for supervisors [50]. They have to focus more on employees' output instead of presence at the office.

More studies are needed that analyze employees' working conditions in relation to performance and health-related behavior both before and after transferring to flexible work arrangements in open work spaces. Field studies that proved the relationships of this study would be highly valuable. In addition, longitudinal research should include a control group. Studies performed in laboratories might be an alternative because they allow for higher control but limit generalizability due to artificial settings and study participants.

\section{Conclusions}

The findings of this study provide new information on effects of a transition to open work spaces including $\mathrm{ABW}$ on employees' job demands, job resources and well-being outcomes. The study showed some beneficial effects in reducing mental job demands and in increasing several job resources such as job autonomy. Overall, these findings seem to indicate that flexible work arrangements are related to some positive effects on employees' perceived occupational stress, psychological detachment from work and need for recovery. However, we are aware on the methodological limitations that might have been influencing the results.

This study built a basis for future longitudinal research on the effects of flexible work arrangements in open work spaces. Future research studies are needed to investigate different relations between flexible work arrangements such as $\mathrm{ABW}$ and job performance as well as health-related outcomes.

\section{Abbreviations}

ABW: Activity Based Working; F: F-test value; M: Mean; RM ANOVA: Repeated measures analysis of variance; RM MANOVA: Repeated measures multivariate analysis of variance; SD: Standard Deviation

\section{Acknowledgments}

We like to thank all employees who participated in this study.

\section{Authors' contributions}

Conceptualization, S.M., R.S., V.H.; methodology, S.M., R.S.; data curation and analysis, S.M.; writing —original draft preparation, S.M.; writing—review and editing, S.M., R.S., V.H.; visualization, S.M.; supervision, V.H.References. The authors read and approved the final manuscript.

\section{Funding}

This research received no external funding.

\section{Availability of data and materials}

The data analyzed during the current study are not publicly available due to German national data protection regulations.

\section{Ethics approval and consent to participate}

The study was approved by the Medical Ethics Committee of the Hamburg Medical Association, Germany (Ethic-Code PV5652). The ethical aspects were in full agreement with the Helsinki declaration.
Prior to data collection, all respondents were informed about the aims of the study and data confidentiality, and gave written informed consent. All participants took part in the survey voluntarily.

\section{Consent for publication}

Not applicable.

\section{Competing interests}

The authors declare that they have no competing interests.

\section{Author details}

${ }^{1}$ Institute for Occpuational Medicine and Maritime Medicine (ZfAM), University Medical Center Hamburg-Eppendorf (UKE), Hamburg, Germany.

${ }^{2}$ Rosenheim University of Applied Sciences, Rosenheim, Germany.

Received: 29 July 2019 Accepted: 11 March 2020

Published online: 19 March 2020

\section{References}

1. Ten Brummelhuis $L L$, Bakker $A B$, Hetland J, Keulemans $L$. Do new ways of working foster work engagement? Psicothema. 2012;24(1):113-20.

2. Engelen L, Chau J, Young S, Mackey M, Jeyapalan D, Bauman A. Is activitybased working impacting health, work performance and perceptions? A systematic review. Building Research Information. 2019;47(4):468-79.

3. Appel-Meulenbroek R, Janssen I. An end-user's perspective on activity-based office concepts. J Corporate Real Estate. 2011;13(2):122-35.

4. Brunia S, De Been I, Van der Voordt T. Accommodating new ways of working: lessons from best practices and worst cases. J Corporate Real Estate. 2016;18(1):30-47.

5. Seddigh A. Office type, performance and well-being. A study of how personality and work tasks interact with contemporary office environments and ways of working. Malmö, Sweden: Stockholm University, Department of Psychology; 2015

6. De Croon E, Sluiter J, Kuijer PP, Frings-Dresen M. The effect of office concepts on worker health and performance: a systematic review of the literature. Ergonomics. 2005;48(2):119-34.

7. Bailey DE, Kurland NB. A review of telework research: findings, new directions, and lessons for the study of modern work. J Organ Behav. 2002; 23:383-400.

8. Mann S, Holdsworth L. The psychological impact of teleworking: stress, emotions and health. N Technol Work Employ. 2003;18:196-211.

9. Bodin Danielsson C, Chungkham HS, Wulff C, Westerlund H. Office design's impact on sick leave rates. Ergonomics. 2014;57(2):139-47.

10. Ter Hoeven $\mathrm{CL}$, van Zoonen $\mathrm{W}$, Fonner $\mathrm{KL}$. The practical paradox of technology: the influence of communication technology use on employee burnout and engagement. Commun Monogr. 2016;83(2):239-63.

11. Cooper CD, Kurland NB. Telecommuting, professional isolation and employee development in public and private organizations. J Organization Behav. 2002;23:511-32.

12. Golden TD, Veiga JF, Simsek Z. Telecommuting's differential impact on work-family conflict: is there no place like home? J Appl Psychol. 2006;91: 1340-50.

13. Wohlers C, Hertel G. Choosing where to work at work - towards a theoretical model of benefits and risks of activity-based flexible offices. Ergonomics. 2016;60(4):467-86.

14. Bakker AB, Demerouti E. The job demands-resources model: state of the art. J Manag Psychol. 2007;22:309-28.

15. Demerouti E, Bakker AB, Nachreiner F, Schaufeli WB. The job demandsresources model of burnout. J Appl Psychol. 2001:86:499-512.

16. Meijman TF, Mulder G. Psychological aspects of workload. In: PJD D, Thierry $\mathrm{H}$, editors. Handbook of work and organizational psychology. Hove: Psychology Press; 1998. p. 5-33.

17. Siltaloppi M, Kinnunen U, Feldt T. Recovery experiences as moderators between psychosocial work characteristics and occupational well-being Work Stress. 2009;23(4):330-48

18. Sonnentag S, Bayer UV. Switching off mentally: predictors and consequences of psychological detachment from work during off-job time. J Occup Health Psychol. 2005;10(4):393-414.

19. Van Steenbergen EF, Van der Ven C, Peeters MCW, Taris TW. Transitioning Towards New Ways of Working: Do Job Demands, Job Resources, Burnout, and Engagement Change? Psychological Reports. 121(4):736-66 Article first 
published online: November 14, 2017; Issue published: August 1, 2018 2018, 121(4):736-766.

20. Sonnentag S, Fritz C. Recovery from job stress: the stressor-detachment model as an integrative framework. J Organ Behav. 2015;36(1):72-103.

21. Nübling M, Hasselhorn HM. The Copenhagen psychosocial questionnaire in Germany: from the validation of the instrument to the formation of a jobspecific database of psychosocial factors at work. Scand J Public Health. 2010;38:120-4.

22. Prümper J, Hartmannsgruber K, Frese M. KFZA. Kurz-Fragebogen zur Arbeitsanalyse. Zeitschrift für Arbeits- und Organisationspsychologie. 1995; 39(3):125-32.

23. Downs CW, Hazen MD. Communication satisfaction questionnaire. In: Downs CW, Adrian AD, editors. Assessing organizational communication. New York: Guilford; 1977. p. 139-57.

24. Downs CW, Hazen MD. A factor analytic study of communication satisfaction. J Bus Commun. 1977;14(3):63-73.

25. Zwijze-Koning KH, de Jong MDT. Measurement of communication satisfaction. Evaluating the communication satisfaction questionnaire as a communication audit tool. Manag Commun Q. 2007;20(3):261-82.

26. Pejtersen JH, Kristensen TS, Borg V, Bjorner JB. The second version of the Copenhagen psychosocial questionnaire. Scand J Public Health. 2010;1:8-24.

27. Van Veldhoven M, Broersen S. Measurement quality and validity of the "need for recovery" scale. Occup Environ Med. 2003;60(1):3-9.

28. Sonnentag S, Fritz C. The recovery experience questionnaire: development and validation of a measure for assessing recuperation and unwinding from work. J Occup Health Psychol. 2007;12(3):204-21.

29. Tabachnick BG, Fidell LS. Using multivariate statistics, vol. 7. Boston: Pearson; 2019.

30. Field A. Discovering statistics using SPSS, vol. 5. London: Sage; 2018.

31. Shapiro SS, Wilk MB. An analysis of variance test for normality (complete samples). Biometrika. 1965;52(3/4):591-611.

32. Cohen J. Statistical power analysis for the behavioral sciences. Hillsdale: Lawrence Erlbaum Associates; 1988.

33. Mazmanian M, Orlikowski WJ, Yates J. The autonomy paradox: the implications of mobile email devices for knowledge professionals. Organ Sci. 2013;24(5):1337-57.

34. Kelliher C, Anderson D. Doing more with less? Flexible working practices and the intensification of work. Hum Relat. 2010;63(1):83-106.

35. Lott Y, Chung H. Gender discrepancies in the outcomes of schedule control on overtime hours and income in Germany. Eur Sociol Rev. 2016;32(6):75265 .

36. Chung $\mathrm{H}$, van der Horst M. Flexible working and unpaid overtime in the UK: the role of gender, Parental and Occupational Status. Social Indicators Research; 2018.

37. V. L. M CJS. Towards responsible workplace innovation: The rise of NWW in public knowledge organizations and their impact on governance. In: International ICE Conference Engineering, Technology and Innovation; 2014.

38. Kim J, Candido C, Thomas L, de Dear R. Desk ownership in the workplace: the effect of non-territorial working on employee workplace satisfaction, perceived productivity and health. Build Environ. 2016. https://doi.org/10. 1016/j.buildenv.2016.04.015:203-214.

39. Sardeshmukh SR, Sharma D, Golden TD. Impact of telework on exhaustion and job engagement: a job demands and resources model. N Technol Work Employ. 2012;27:193-207.

40. Kelliher C, Anderson D. For better or for worse? Analysis of how flexible working practices influence employees perceptions of job quality. Int J Hum Resour Manag. 2008;19:419-31.

41. Blok M, Groenesteijn L, Schelvis R, Vink P. New ways of working: does flexibility in time and location of work change work behavior and affect business outcomes? Work. 2012;41:2605-10.

42. Robertson MM, Huang Y-H, O'Neill MJ, Schleifer LM. Flexible workspace design and ergonomics training: impacts on the psychosocial work environment, musculoskeletal health, and work effectiveness among knowledge workers. Appl Ergon. 2008;39(4):482-94.

43. Moen P, Kelly EL, Fan W, Lee S-R, Almeida D, Kossek EE, Buxton OM. Does a flexibility/support organizational initiative improve high-tech employees' well-being? Evidence from the work, family, and health network. Am Sociol Rev. 2016;81(1):134-64.

44. Nijp HH, Beckers DGJ, van de Voorde K, Geurts SAE, Kompier MAJ. Effects of new ways of working on work hours and work location, health and jobrelated outcomes. Chronobiol Int. 2016;33(6):604-18.
45. Seddigh A, Berntson E, Bodin Danielson C, Westerlund H. Concentration requirements modify the effect of office type on indicators of health and performance. J Environ Psychol. 2014;38:167-74.

46. Mellner C, Kecklund G, Kompier M, Sariaslan A, Aronsson G. Boundaryless work, psychological detachment and sleep: does working 'anytime anywhere' equal employees are 'always on'? New Ways Working Pract. 2016; 1:29-47.

47. Nielsen K, Abildgaard JS. Organizational interventions: a research-based framework for the evaluation of both process and effects. Work Stress. 2013; 27(3):278-97.

48. Engelen L, Chau J, Bohn-Goldbaum E, Young S, Hespe D, Bauman A. Is active design changing the workplace? - a natural pre-post experiment looking at health behaviour and workplace perceptions. Work. 2017;56(2): 229-37.

49. Vorobeychik Y, Joveski Z, Yu S. Does communication help people coordinate? PLoS ONE. 2017;12(2):e0170780. https://doi.org/10.1371/journal. pone. 0170780

50. Payne HJ. Examining the relationship between Trust in SupervisorEmployee Relationships and Workplace Dissent Expression. Communication Research Reports. 2014;31(2):131-40.

\section{Publisher's Note}

Springer Nature remains neutral with regard to jurisdictional claims in published maps and institutional affiliations.

\section{Ready to submit your research? Choose BMC and benefit from:}

- fast, convenient online submission

- thorough peer review by experienced researchers in your field

- rapid publication on acceptance

- support for research data, including large and complex data types

- gold Open Access which fosters wider collaboration and increased citations

- maximum visibility for your research: over $100 \mathrm{M}$ website views per year

At BMC, research is always in progress.

Learn more biomedcentral.com/submissions 